\title{
Implementation of a recovery-oriented model in a sub-acute Intermediate Stay Mental Health Unit (ISMHU)
}

Barry G. Frost ${ }^{1,2}$, Megan Turrell ${ }^{3}$, Ketrina A. Sly 2,3,4,6, Terry J. Lewin ${ }^{2,3,4,6^{*}}$, Agatha M. Conrad ${ }^{2,3,4,6}$, Suzanne Johnston ${ }^{3}$, Srinivasan Tirupati ${ }^{3,4}$, Kerry Petrovic $^{5}$ and Sadanand Rajkumar ${ }^{3,4}$

\begin{abstract}
Background: An ongoing service evaluation project was initiated following the establishment of a new, purpose-built, 20-bed sub-acute Intermediate Stay Mental Health Unit (ISMHU). This paper: provides an overview of the targeted 6-week program, operating within an Integrated Recovery-oriented Model (IRM); characterises the clients admitted during the first 16 months; and documents their recovery needs and any changes.

Methods: A brief description of the unit's establishment and programs is initially provided. Client needs and priorities were identified collaboratively using the Mental Health Recovery Star (MHRS) and addressed through a range of in-situ, individual and group interventions. Extracted client and service data were analysed using descriptive statistics, paired t-tests examining change from admission to discharge, and selected correlations.

Results: The initial 154 clients (165 admissions, average stay $=47.86$ days) were predominately male $(72.1 \%)$, transferred from acute care (75.3\%), with schizophrenia or related disorders (74.0\%). Readmission rates within 6-months were $16.2 \%$ for acute and 3.2\% for sub-acute care. Three MHRS subscales were derived, together with stage-of-change categories. Marked improvements in MHRS Symptom management and functioning were identified ( $z$-change $=-1.15)$, followed by Social-connection ( $z$-change $=-0.82)$ and Self-belief $(z$-change $=-0.76)$. This was accompanied by a mean reduction of 2.59 in the number of pre-action MHRS items from admission to discharge $(z$-change $=0.98$ ). Clinician-rated Health of the Nation Outcome Scales (HoNOS) improvements were smaller ( $z$-change $=0.41$ ), indicative of illness chronicity. Staff valued the elements of client choice, the holistic and team approach, program quality, review processes and opportunities for client change. Addressing high-levels of need in the 6-week timeframe was raised as a concern.

Conclusions: This paper demonstrates that a recovery-oriented model can be successfully implemented at the intermediate level of care. It is hoped that ongoing evaluations support the enthusiasm, commitment and feedback evident from staff, clients and carers.
\end{abstract}

Keywords: Health service evaluation, Inpatients, Mental disorders, Mental health services, Recovery, Rehabilitation, Serious mental illness, Sub-acute

\footnotetext{
* Correspondence: Terry.Lewin@hnehealth.nsw.gov.au

${ }^{2}$ Centre for Brain and Mental Health Research, University of Newcastle, Callaghan, NSW 2308, Australia

${ }^{3}$ Hunter New England Mental Health, Newcastle, NSW 2300, Australia

Full list of author information is available at the end of the article
} 


\section{Background}

\section{Recovery frameworks}

In the absence of research data, the consumer movement identified a range of issues profoundly influencing their mental health $(\mathrm{MH})$ and role functioning, including hopelessness, dependence, lack of control and loss of sense of self, which has led to the emergence of a positively focused recovery-oriented model [1]. This model assumes that people with a serious mental illness (SMI) have the capacity to develop a stronger sense-of-self and mastery and to pursue a life not defined by their illness. Indeed, research has shown $50-70 \%$ of people with a SMI experience high levels of recovery and improvement [2], with the frequency and periods of wellness increasing with age [1].

While the term 'recovery' is used in varied ways [1, 3-6], it nevertheless conveys an unequivocal message of a better future. With respect to $\mathrm{MH}$, recovery may occur on a personal and/or a clinical level; however, until recently the focus has been almost exclusively on clinical recovery [7]. Typically, clinical recovery is "... primarily defined by mental health professionals and pertains to a reduction or cessation of symptoms and restoring social functioning" ([8], p. 2), while personal recovery refers to "... being able to create and live a meaningful and contributing life in a community of choice with or without the presence of mental health issues" ([9], p. 4).

Personal recovery has been conceptualised as an active process, focused on the achievement of a satisfying and fulfilling role, irrespective of symptoms [10]. That is, recovery reflects a shift from a passive to an active senseof-self, from dependent to self-determining and from isolation to connectedness [6]. Although the recovery pathway is often complex and non-linear, hope is critical in shaping and sustaining improvements and social inclusion $[11,12]$.

Importantly, recovery is both a process and an outcome, and consumer descriptions (eg, of personal wellbeing and social inclusion) need to be incorporated within recovery-oriented services to improve service outcomes [13]. Encouraging clients to assume greater independence is axiomatic to 'Clinical Rehabilitation' [14] and consistent with the key elements of personal recovery. Although processes and outcomes can be difficult to distinguish, the greater the symptomatic and functional improvement, the higher the expected levels of hope, empowerment, self-responsibility and autonomy [1].

\section{Recovery-oriented service provision}

Australian $\mathrm{MH}$ services are currently in transition, including national reviews of programs and services [15], development of a new MH Care Classification [16], and introduction of health service wide Activity Based
Funding [17]. Concurrently, attempts have been made to formulate a 'national framework for recovery-oriented mental health services' - to provide guidance for practitioners and service providers [18] and to outline relevant research, conceptual and policy underpinnings [9]. Similar 'recovery-focused' frameworks have been developed elsewhere [5, 19]. For example, in the United Kingdom templates and guides have been produced for many aspects of $\mathrm{MH}$ service provision, including 'rehabilitation services' (eg, [20, 21]), for which the contemporary definition is: "... recovery-oriented service for people with disabilities associated with longer-term mental health problems" ([21], p. 10).

Recovery-oriented service provision can occur in a multitude of forms. "The notion of recovery does not equate with a particular model of care ... or service setting"; rather, 'recovery' can be viewed as "an overarching philosophy that encompasses ... self-determination, self-management, personal growth, empowerment, choice and meaningful social engagement" ([8], p. 2). We have adopted the following definition: recoveryoriented service delivery "... is centered on and adapts to people's aspirations and needs, rather than people having to adapt to the requirements and priorities of services" and it has a "...responsibility to provide evidence-informed treatment, therapy, rehabilitation and psychosocial support that assist in achieving the best outcomes for people's mental health, physical health and wellbeing" ([9], p. 26).

Five 'practice domains' (covering 17 capabilities) have been identified within the proposed national recoveryoriented framework for $\mathrm{MH}$ services: promoting hope and optimism; adopting a person-centred and holistic perspective; supporting personal recovery; developing an appropriate organisational culture and skilled workforce; and action on social inclusion and social determinants [18]. These domains and capabilities are largely consistent with the synthesis of recovery-oriented practice guidance provided by Le Boutillier et al. [19].

In developing recovery-oriented but often time limited $\mathrm{MH}$ programs, some of the key elements requiring consideration are: methods for identifying current client needs and priorities; selection of appropriate assessment and outcome measures; devising tailored evidence-based interventions (EBIs); engagement with families and carers; and strategies for fostering ongoing community/social linkages. The task of improving $\mathrm{MH}$ can also be expressed in other ways. For example, many researchers propose that outcomes can be improved through better access to psychosocial EBIs [22-27]. Evidenced-based practices are consistent with the recovery model provided that the client is encouraged and supported to assume responsibility in the domains of need, at the earliest possible opportunity. 
Providing adequate staff training in the flexible delivery of recovery-oriented programs is also an ongoing issue for mental health services $[28,29]$.

\section{The current study}

Elsewhere we have described a general recovery-oriented framework for $\mathrm{MH}$ services, which has been characterised as an Integrated Recovery-oriented Model (IRM) [14]. 'Clinical Rehabilitation' approaches, practices and practitioners are viewed as pivotal, utilising EBIs and processes to help achieve and maintain optimal functioning and to promote recovery, self-agency and social inclusion. The IRM was designed to address the recovery needs of people with a SMI by improving access to a suite of EBIs provided in an integrated, multi-layered service context that: 1) remediates symptoms and reinstates hope (primarily via acute/emergency $\mathrm{MH}$ services; 2) restores and rebuilds competencies (primarily via specialised $\mathrm{MH}$ Clinical Rehabilitation services); and 3) provides opportunities to reconnect with place and society (primarily via General Practitioners, and Community Managed and Non-government Organisations providing integrated community services) [14].

Almost by definition, it is not possible to formulate a 'one-size fits all' strategy for providing recovery-oriented $\mathrm{MH}$ services, with clients at different recovery stages needing access to different EBIs (ie, the 'right care' at the 'right time') [30]. In this paper, we illustrate the application of recovery-oriented practices at the 'intermediate' level of care; that is, within a specialised sub-acute inpatient $\mathrm{MH}$ context (see Additional file 1 for detailed definitions), in which each client's strengths, capabilities and needs can be observed and adequately assessed, and they can be progressively exposed to more intensive, personalised and group interventions - with the ultimate goal of stabilising and improving their recovery trajectory.

The aims of this paper are three-fold: 1) to briefly document the establishment of the Intermediate Stay Mental Health Unit (ISMHU) and the implementation of an IRM within a targeted 6-week sub-acute inpatient program; 2) to characterise the clients admitted during the unit's first 16 months of operation; and 3) to quantify their recovery needs and priorities on admission and any changes during the admission.

\section{Methods}

\section{Study design}

The current paper is part of an ongoing service evaluation project, with data drawn primarily from regional clinical records associated with the participating unit, and all processing and analysis undertaken by $\mathrm{MH}$ service staff. This project was viewed as an internal, low risk study and exempted from the requirement for a formal regional ethics committee application.

\section{Intermediate Stay Mental Health Unit (ISMHU)} Establishment, service context, staffing and training strategy In 2005, New South Wales Health commenced planning for the establishment of a number of 20-bed sub-acute/ non-acute inpatient units [30, 31]. Improved access to recovery-focused rehabilitation services that are highly integrated and rigorously evaluated was the primary goal. To-date, eight units have been established (totalling 140 beds), although they vary in their models of care and their typical lengths of stay (eg, [32]).

The new, purpose-built, 20-bed, sub-acute ISMHU within Hunter New England Mental Health services (Newcastle, Australia) opened in November 2010, with the specific intention of providing a planned, 6-week, recovery-focused intervention program. To optimise access, the criteria for ISMHU admission and transfer were kept to a minimum. The primary focus was the recovery needs and priorities of adults aged 16-65 years with a SMI who were not acute and considered to be at low risk.

The ISMHU service model and 6-week program were developed under the stewardship of a representative committee. In broad terms, this program was designed to operate within the framework of an IRM for MH services that seeks to support and promote 'remediation, restoration and reconnection' [14]. As noted above, specialised Clinical Rehabilitation approaches were regarded as central (eg, utilising recovery-focused EBIs and processes). The specific goals of the ISMHU program were: to improve psychological and physical wellness; enhance personal and interpersonal coping skills; improve daily functioning; enhance social, family and community supports; and, thereby, to encourage a new or higher sense of self-management and social inclusion through the attainment of socially valued roles.

With regards to staffing, the ISMHU program also departed somewhat from traditional Australian approaches to $\mathrm{MH}$ service delivery, including adjustments to recruitment strategies, staffing profiles, training programs and roster arrangements. Some of these specific elements included: staff recruitment against a predetermined set of values and skills (eg, openness, empathy, support for responsible risk taking); a broader mix of allied health staff; a senior rehabilitation clinician functionally 'embedded' in acute inpatient and community-based $\mathrm{MH}$ services, to ensure appropriate and timely ISMHU referrals; a Non-government Organisation peer-link worker liaising closely with community-based day programs; and a range of work day and after-hours programs. See Additional file 1 for further information about ISMHU's establishment, service context (recovery-oriented service delivery and sub-acute classifications), staffing and training strategy. 


\section{Program}

To underpin the ISMHU recovery-oriented approach, the Mental Health Recovery Star (MHRS), a collaborative planning, review and assessment tool was adopted [33]. Essentially, the MHRS provides a straightforward framework for conducting a structured conversation with clients, which, in the current context, was undertaken during the first and last few days of the ISMHU stay. To support the collaborative development of an intervention plan built around the MHRS domains, a MHRS program guide was developed. The programs were collaborative, goal-focused, evidence-based and motivational, promoted generalisation, accommodated different learning styles and were structured to support achievement. The guide mapped the goals and interventions available in each of the ten potential domains and included core programs and electives. Importantly, time limited programs can only address some of the relevant recovery domains for each person; consequently, in addition to identifying medium- to longer-term recoveryoriented goals, collaborative assessments using the MHRS were used to help set priorities for each person for the subsequent 6 weeks.

Key elements of the ISMHU program are summarised in Table 1. These elements included opportunities for in situ interventions as well as more formal individual and group programs, which could be unit and/or community-based; where possible, they were also coupled with interventions provided through community-based rehabilitation teams. For clients who were unable or unwilling to participate in core programs, activity-based engagement programs were also offered. Family interventions were offered on an ongoing basis in both group and individual formats.

\section{Measures}

\section{Mental Health Recovery Star (MHRS)}

The MHRS [33], developed using a bottom-up approach [34], was designed to be a collaborative tool for assessing and discussing recovery experiences, needs and priorities across ten potential domains, and to guide recovery plans and interventions. Each domain is underpinned by a detailed stage-of-change hierarchy [35] and graphically represented as a ladder (from 1 to 10) within a tenpointed star; ladder steps are characterised separately for each domain but also labelled generically as: Stuck (1-2); Accepting help (3-4); Believing (5-6); Learning (7-8); and Self-reliance (9-10) [33].

The MHRS was collaboratively completed by individual clients with guidance from the clinician coordinating their care. All available ISMHU-related data for the MHRS was downloaded from the associated online program and supplemented by a manual search of clinical records (for additional completed MHRS forms). Where possible, two sets of ratings were identified, one within a few days of admission and one near ISMHU discharge; on average $(N=94)$, the interval between these ratings was 37.9 days $(\mathrm{SD}=17.4)$.

The MHRS has demonstrated high internal consistency in UK samples (Cronbach's $\alpha=0.85$ ) [36] and good testretest reliability at twelve days (ICC's $>0.7$ ), as well as high acceptability and ease of use [37]. As detailed in our preliminary MHRS dimensionality analyses (see Additional file $2, N=228$ sets of ratings), a single factor solution does a reasonably good job at accounting for variation among the item ratings (Cronbach's $\alpha=0.88$ ), providing strong justification for forming an overall MHRS score based on (averaging) the 10 items. In addition, it also seems reasonable to construct three correlated MHRS subscale scores, which may be particularly useful for examining change and differential predictive utility: 'Symptom management and functioning' (averaging four domains: Physical health and self-care; Managing mental health; Work; and Living skills) (Cronbach's $\alpha=0.78$ ), 'Self-belief' (averaging four domains: Addictive behaviour; Identity and self-esteem; Trust and hope; and Responsibilities) (Cronbach's $\alpha=0.74$ ); and 'Social connection' (averaging two domains: Relationships; and Social networks) (Cronbach's $\alpha=0.69$ ).

\section{Routine service outcome measures}

Clinical and basic demographic data for all ISMHU admissions were obtained from electronic clinical records via the regional Inpatient Management System (IPMS). Selected assessment measures, routinely collected as part of the national outcomes set [38], were obtained via the regional Clinical Information and Management Exchange (CHIME), including: the Health of the Nation Outcomes Scales (HoNOS; [39]); and the Kessler psychological distress scale (K10; [40]). Twelve items are assessed in the HoNOS: problems with behaviour (3 items); impairment (2 items); symptoms (3 items); and social functioning (4 items). Items are rated on a 5-point scale ranging from (0) 'no problem' to (4) 'severe to very severe problem', with higher scores indicating poorer mental health [39]. Admission and discharge HoNOS ratings were often completed by different ISMHU clinicians. The HoNOS has displayed good construct and predictive validity, with adequate test-retest and inter-rater reliability and sensitivity to change $[41,42]$. The K10 was completed by individual clients at ISMHU, as a measure of general psychological distress (during the last month); it is a 10 item measure, with higher scores indicating greater distress (range 10-50), which has been shown to have consistent psychometric properties across a range of samples [40]. 


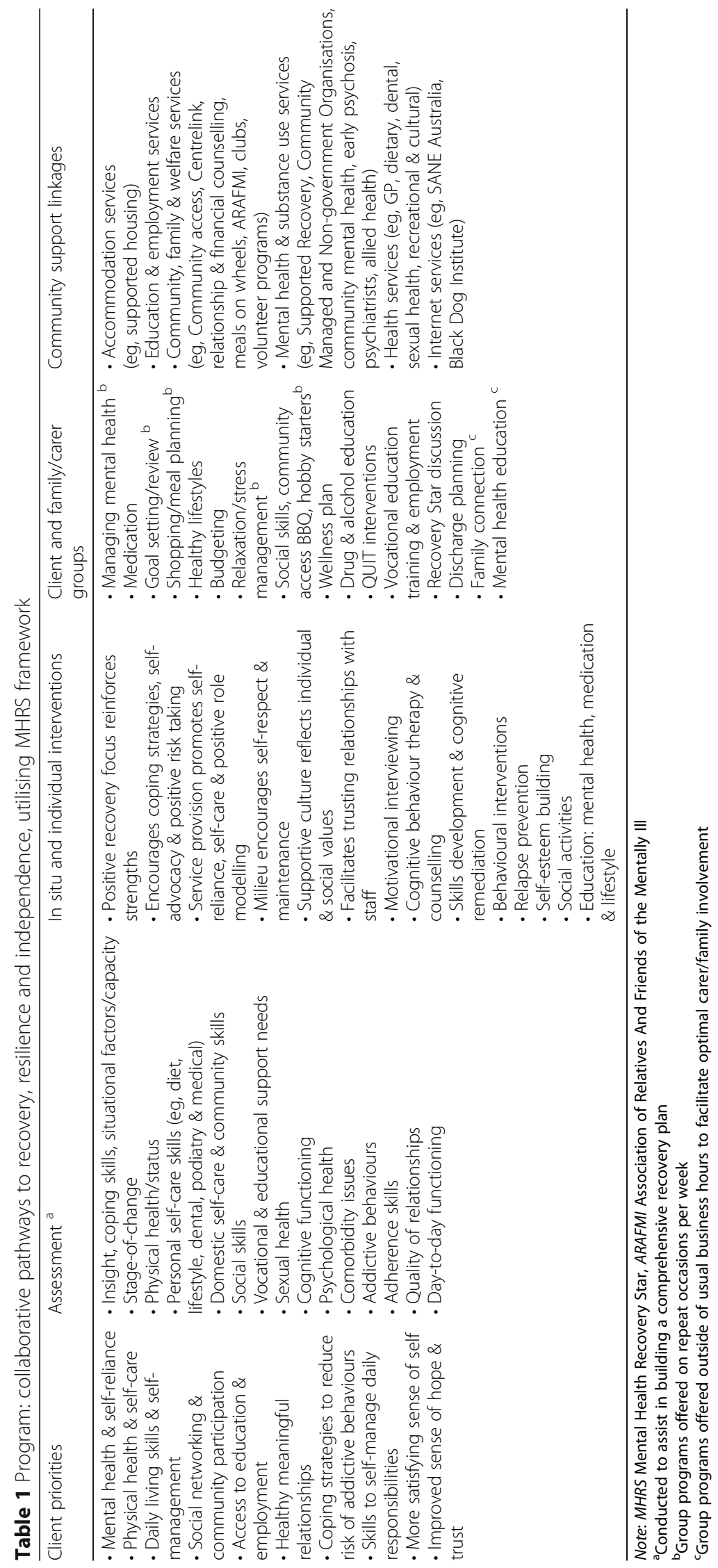




\section{Data analysis}

For the current analyses, the relevant data collection window was from the opening of ISMHU in November 2010 up until March 31st, 2012. IBM SPSS statistical software (Version 22.0; Armonk, NY, USA) was used to analyse the aggregated datasets. Many of the statistics reported here are descriptive, with paired t-tests used to examine change scores from admission to discharge, and bivariate correlations used to examine relationships between these change scores. As a partial control for the number of statistical tests, the threshold for statistical significance was set at $p<0.01$.

\section{Results}

\section{Client characteristics}

ISMHU commenced operation at $50 \%$ capacity, with the remaining beds opened prior to March 2011. By the end of March 2012, the unit had received 165 admissions from 154 clients. Table 2 details the socio-demographic and clinical characteristics of these clients, who averaged 37.25 years of age, were predominantly male $(72.1 \%)$ and transferred from acute inpatient units (75.3\%).

Consistent with expectations, $56.5 \%$ of admissions were voluntary, with $74.0 \%$ having an ICD-10 diagnosis of schizophrenia or a related disorder. The next most common diagnoses were anxiety or a related disorder (44.2\%), substance misuse (41.6\%) and depression (24.7\%); the vast majority of clients also reported psychosocial (94.8\%) and/or physical health (87.7\%) problems. On admission, the majority of clients $(57.0 \%)$ had current functioning ratings in the mild category (0-9) on the HoNOS, with a similar percentage (56.9\%) experiencing low or moderate distress (10-21) on the K10.

The average length of stay was 47.86 days, with $50.0 \%$ staying for 41 to 60 days. For those staying longer than 60 days (23.4\%), the major reason was the complexity and/or acuity of issues identified. For $10.4 \%$ of clients the discharge destination was an acute inpatient facility. During the first 16 months, bed occupancy was 80.6\% (ignoring client leave periods) and the average number of leave days was 6.75 (median of 5.00 ); $83.8 \%$ of admissions were associated with at least one leave period, with the first period commencing at a median of 25 days from admission. Although planned or transitional leave arrangements carry a service cost, the benefits accrued in supporting social connectedness and promoting confidence and self-sufficiency (as clients transitioned from a structured environment to community living) were considered to more than offset these costs. In the 6-month period following the index admission, 28 clients had a subsequent readmission, with $16.2 \%$ (25/154) admitted to an acute unit and $3.2 \%(5 / 154)$ re-admitted to ISMHU ( 2 individuals had both an acute and sub-acute component to their subsequent stay).

\section{Initial feedback}

As part of the initial service review, ISMHU staff from across all disciplines volunteered to provide feedback on the model of care and unit performance; staff feedback sessions were held between February and March 2012, with 14 staff participating (or approx. 54\%). They identified a number of achievements, as well as areas for improvement. In particular, staff valued: the model of care; client choice and self-determination; the multidisciplinary, holistic approach; quality of groups and education sessions; client review processes; opportunities to support change; significance of the work undertaken; interagency connections, family and carer involvement; discharge practices; and ISMHU's built environment. Medical staff were appreciative of the opportunity to work intensively with clients in a supportive timeframe.

The feedback from clients, carers and families has been both formal and informal. A review of feedback collection methods has suggested that more reliable and effective methods need to be developed. Two examples of written feedback were: "What can we say when thank you just isn't enough! I can't tell you how grateful I am to each and every one of you who cared for [person's name] while he was a patient at ISMHU"; and "Thank you for being flexible, not serious and not being negative. Thanks for all the happiness and plenty of smiles. I had forgotten what it felt like to be normal and thank you for your support."

There were also several suggested areas for improvement: reconciling the recovery-oriented approach with involuntary admissions; management of clients with elevated levels of risk; recovery-oriented training and supervision; insufficient day shift nursing staff; care coordination; and insufficient time during 6-weeks to effectively intervene. Some staff also suggested there should be greater flexibility in length of stay (eg, 9weeks or a split unit with 6- and 9-week stays).

\section{MHRS profiles}

To date, the MHRS does not have an agreed reporting format; however, we encourage other researchers and clinicians to explore usage of the subscales detailed in Additional file 2, as well as the stage-of-change categories in Table 3. For convenience, we chose a simple additional metric for characterising MHRS, namely the percentages below 6 ('Pre-action'), from 6 to below 9 ('Action'), and between 9 and 10 ('Self-reliant' stage). To support our descriptive label for the first cut-point, it should be noted that the generic MHRS descriptor for step 5 includes: "... The next step is to act on this change" [33]. Arguably, scores categorised as 'pre-action' require some form of intervention or other input from services or support networks to help stimulate change and promote recovery. 
Table 2 Client characteristics (November 2010 to March 2012, N=154 clients) ${ }^{a}$

\begin{tabular}{|c|c|c|}
\hline Socio-demographic and clinical characteristics & $N$ & $\%$ \\
\hline \multicolumn{3}{|l|}{ Age $($ Mean $=37.25$ years, $S D=10.20)$ : } \\
\hline Under 25 & 17 & 11.0 \\
\hline $25-39$ & 73 & 47.4 \\
\hline $40-54$ & 57 & 37.0 \\
\hline $55+$ & 7 & 4.5 \\
\hline \multicolumn{3}{|l|}{ Gender } \\
\hline Male & 111 & 72.1 \\
\hline Female & 43 & 27.9 \\
\hline \multicolumn{3}{|l|}{ Referral source } \\
\hline Acute inpatient facility & 116 & 75.3 \\
\hline Community & 38 & 24.7 \\
\hline \multicolumn{3}{|l|}{ Legal status } \\
\hline Voluntary & 87 & 56.5 \\
\hline Involuntary ${ }^{c}$ & 67 & 43.5 \\
\hline \multicolumn{3}{|l|}{ Symptom severity on admission } \\
\hline \multicolumn{3}{|l|}{ HoNOS $(N=114$, Mean $=9.19$, SD $=6.46)$ : } \\
\hline Mild (0-9) & 65 & 57.0 \\
\hline Moderate (10-12) & 19 & 16.7 \\
\hline Severe $(>13)$ & 30 & 26.3 \\
\hline \multicolumn{3}{|l|}{ Current distress on admission } \\
\hline \multicolumn{3}{|l|}{$\mathrm{K} 10(N=79$, Mean $=22.63, \mathrm{SD}=10.01)$} \\
\hline Low (10-15) & 22 & 27.8 \\
\hline Moderate (16-21) & 23 & 29.1 \\
\hline High (22-29) & 13 & 16.5 \\
\hline Very high (30-50) & 21 & 26.6 \\
\hline \multicolumn{3}{|l|}{ Any ICD-10 discharge diagnosis of: ${ }^{b}$} \\
\hline Schizophrenia or related & 114 & 74.0 \\
\hline Anxiety or related & 68 & 44.2 \\
\hline Substance misuse & 64 & 41.6 \\
\hline Depression & 38 & 24.7 \\
\hline Bipolar disorder & 22 & 14.3 \\
\hline Personality disorder & 12 & 7.8 \\
\hline Other mental health problems & 15 & 9.7 \\
\hline Psychosocial problems & 146 & 94.8 \\
\hline Physical health problems & 135 & 87.7 \\
\hline \multicolumn{3}{|l|}{ Length of stay (Mean $=47.86$ days, $S D=24.16$ ) } \\
\hline Early exit (0 to 7 days) & 8 & 5.2 \\
\hline Shorter than planned (8 to 40 days) & 33 & 21.4 \\
\hline As planned (41-60 days) & 77 & 50.0 \\
\hline Longer than planned (Over 60 days) & 36 & 23.4 \\
\hline
\end{tabular}


Table 2 Client characteristics (November 2010 to March 2012, N=154 clients) ${ }^{\mathrm{a}}$ (Continued)

\begin{tabular}{|c|c|c|}
\hline \multicolumn{3}{|l|}{ Discharge destination } \\
\hline Community & 138 & 89.6 \\
\hline Acute Inpatient facility ${ }^{c}$ & 16 & 10.4 \\
\hline \multicolumn{3}{|c|}{ Readmission within 6 months to } \\
\hline Acute inpatient unit & 25 & 16.2 \\
\hline Sub-acute inpatient unit & 5 & 3.2 \\
\hline
\end{tabular}

Table 3 summarises MHRS profiles for the 131 clients with available admission data. The items revealing the highest need/priority (ie, based on lower mean ratings) were: Work (or work-like activity), Social networks, Relationships, Managing $\mathrm{MH}$ and Identity and selfesteem; all of these items had median MHRS ratings of 5.00. Clients typically required support in, at least, four or five domains (mean number of pre-action items $=4.76$ ).

\section{Improvements during admission}

Admission to discharge change profiles for the HoNOS, MHRS subscales and overall score are displayed in the left-hand columns of Table 4; these analyses were based on all available data pairs. While all analyses demonstrated significant improvements across the course of the 6-week admission, there were more marked improvements on the MHRS Symptom management and functioning subscale (mean $z$-change $=-1.15$ ) compared with, for example, the MHRS Self-belief subscale (mean $z$-change $=-0.76$ ). Clinician rated HoNOS scores, based on 82 admission and discharge pairs, displayed the smallest change (mean $z$-change $=0.41$ ), perhaps reflective of the sub-acute but nevertheless chronic and debilitating nature of the clients' illnesses. Using the simplified HoNOS 'meaningful outcome' classification method described by Parabiaghhi et al. [43]: 42.7\% (35/82) 'improved to mild' (ie, a HoNOS reduction $\geq 4$, and shifting into the mild category); $52.4 \%$ were 'stable' (33 with 'mild', 5 with 'moderate' and 5 with 'severe' HoNOS scores at discharge); and 4.9\% (4/82) 'deteriorated' (ie, HoNOS worsening by $\geq 4$ ). There was a relative absence of correlations between change scores from clinicians and clients (although different measures were used; see the right-hand columns of Table 4), suggesting that they tended to have different perspectives. There was also a substantial improvement in stage-of-change, as evidenced by a reduction in the number of pre-action

Table 3 Mental Health Recovery Star (MHRS) profiles on admission ( $N=131$ )

\begin{tabular}{|c|c|c|c|c|c|}
\hline \multirow[t]{2}{*}{ MHRS subscale/items } & \multirow{2}{*}{$\begin{array}{l}\text { Mean } \\
(\mathrm{SD})\end{array}$} & \multirow[t]{2}{*}{ Median } & \multicolumn{3}{|c|}{ Stage-of-change $(\%)^{a}$} \\
\hline & & & Pre-action & Action & Self-reliant \\
\hline Symptom management \& functioning: & $5.69(1.48)$ & 5.75 & 55.7 & 42.7 & 1.5 \\
\hline (2) Physical health and self-care & $6.11(2.05)$ & 6.00 & 42.7 & 45.0 & 12.2 \\
\hline (1) Managing mental health & $5.43(1.86)$ & 5.00 & 58.8 & 35.9 & 5.3 \\
\hline (5) Work & $4.66(1.86)$ & 5.00 & 71.0 & 26.7 & 2.3 \\
\hline (3) Living skills & $6.56(2.32)$ & 7.00 & 37.4 & 35.1 & 27.5 \\
\hline Self-belief: & $6.49(1.49)$ & 6.50 & 34.4 & 59.5 & 6.1 \\
\hline (7) Addictive behaviour ${ }^{b}$ & $6.72(2.49)$ & 7.00 & 33.6 & 39.7 & 26.7 \\
\hline (9) Identity and self-esteem & $5.72(2.13)$ & 5.00 & 50.4 & 37.4 & 12.2 \\
\hline (10) Trust and hope & $5.95(2.08)$ & 6.00 & 44.3 & 45.0 & 10.7 \\
\hline (8) Responsibilities ${ }^{b}$ & $7.58(1.96)$ & 8.00 & 18.3 & 45.0 & 36.6 \\
\hline Social connection: & $5.18(1.93)$ & 5.00 & 63.4 & 32.8 & 3.8 \\
\hline (6) Relationships & $5.34(2.34)$ & 5.00 & 57.3 & 32.1 & 10.7 \\
\hline (4) Social networks & $5.02(2.34)$ & 5.00 & 61.8 & 26.7 & 11.5 \\
\hline Overall score (10 items) & $5.98(1.31)$ & 6.00 & 49.6 & 48.9 & 1.5 \\
\hline
\end{tabular}

Note: Item numbers from the MHRS are shown in brackets; see Additional file 2 for subscale development

${ }^{a}$ Item or subscale score classification: Pre-action $<6$; Action $\geq 6 \&<9$; Self-reliant 9-10; Number of pre-action items: Mean $=4.76$ (SD = 2.60)

${ }^{\mathrm{b}} \mathrm{A}$ score of 10 is given for Addictive behaviour and/or Responsibilities if no difficulties are reported 
Table 4 Change during the admission for selected measures and correlations between change scores

\begin{tabular}{|c|c|c|c|c|c|c|c|c|}
\hline \multirow[t]{2}{*}{ Measure (Number of items) } & \multirow{2}{*}{$\begin{array}{l}\text { Admission } \\
\text { Mean (SD) }\end{array}$} & \multirow{2}{*}{$\begin{array}{l}\text { Discharge } \\
\text { Mean (SD) }\end{array}$} & \multicolumn{2}{|l|}{ Change } & \multicolumn{4}{|c|}{$\begin{array}{l}\text { Selected correlations between change } \\
\text { scores (see Row labels for measures) }\end{array}$} \\
\hline & & & Mean (SD) [z-change] & Paired $t$-test & $\|$ & III & IV & V \\
\hline \multicolumn{9}{|l|}{ Symptom Severity - HoNOS $(N=82)$ : } \\
\hline I. Overall score (12) & $8.66(5.90)$ & $5.96(5.40)$ & $2.70(6.53)[0.41]$ & $3.74^{* *}$ & -.250 & $-.289^{\#}$ & -.112 & -.254 \\
\hline \multicolumn{9}{|l|}{ MHRS $(N=94)$ : } \\
\hline II. Symptom management \& functioning (4) & $5.74(1.46)$ & $7.15(1.40)$ & $-1.41(1.23)[-1.15]$ & $-11.16^{* *}$ & & $.679^{* *}$ & $.676^{* *}$ & $(.899)$ \\
\hline III. Self-belief (4) & $6.61(1.51)$ & $7.61(1.54)$ & $-1.01(1.32)[-0.76]$ & $-7.41^{* *}$ & & & $.626^{* *}$ & $(.892)$ \\
\hline IV. Social connection (2) & $5.26(1.89)$ & $6.78(1.97)$ & $-1.53(1.85)[-0.82]$ & $-7.90^{* *}$ & & & & $(.844)$ \\
\hline V. Overall score (10) & $5.99(1.28)$ & $7.26(1.37)$ & $-1.27(1.22)[-1.04]$ & $-10.09^{* *}$ & & & & \\
\hline Number of pre-action MHRS items ${ }^{a}$ & $4.53(2.57)$ & $1.95(2.48)$ & $2.59(2.63)[0.98]$ & $9.52^{* *}$ & & & & \\
\hline
\end{tabular}

Note: HoNOS Health of the Nation Outcome Scales (12 items: Clinician rated), MHRS Mental Health Recovery Star (Collaboratively completed: Clinician/Client)

${ }^{a}$ Count of MHRS item scores $<6 ;{ }^{*}($ trend, $p<0.05) ;{ }^{*} p<0.01 ;{ }^{* *} p<0.001$

MHRS items from admission to discharge (mean change $=2.59$ items; mean $z$-change $=0.98$ ).

\section{Discussion \\ Implementation of targeted 6-week recovery-focused program}

We have contextualised the ISMHU program within an overarching model of care for MH services (ie, IRM, incorporating specialised Clinical Rehabilitation approaches) [see 14]. This model was developed in parallel with the emerging national recovery-oriented frameworks in Australia $[9,18]$ rather than being a direct product of those initiatives.

Establishing a new unit provided a rare opportunity to develop and implement an innovative recovery-oriented model at the intermediate (sub-acute) level of care. It seems almost self-evident that if the recovery needs and priorities of people with high levels of unmet need are addressed (within a targeted, evidence-based program) and within a positive environment, focused on building independence and social inclusion, then considerable $\mathrm{MH}$ and psychosocial benefits are likely to accrue. Notwithstanding, developing and evaluating $\mathrm{MH}$ services that support and promote recovery is challenging.

The initial success of the ISMHU program has been reflected in the enthusiasm, commitment and feedback received from staff, clients and carers. The concerns expressed by staff during the initial service review may relate to the complexities in addressing the high levels of need within a limited timeframe but with a staffing budget more aligned with traditional non-acute services. It is also possible that the staff concerns may have more to do with the broader acceptance and establishment of the unit than with the underlying model of care. Many staff had very high expectations, even though few, if any, had experience at this level of care.

The benefits of promoting client led recovery in an environment that affords a unique opportunity to address high levels of need, and in a service context that is more consonant with staff, client and family expectations, may be considerable. Stepping outside the orthodoxy may raise many issues, but if the initial feedback can be supported by further research and evaluation evidence then it has certainly been a step worth taking. Individualised approaches to recovery have been applied to vocational rehabilitation, and found to have positive effects not only for employment but on clinical outcomes [44].

The program delivered at ISMHU should probably be viewed as one component, albeit a useful one, within the armoury of potential recovery-oriented intervention programs for individuals with a SMI. It was targeted at the intermediate level of care, program driven but personalised and framed within a broader IRM for MH services. As a planned, limited duration inpatient program, it also facilitated a more comprehensive assessment of current competencies and strengths, enabled trial leave periods and provided opportunities to forge or strengthen community linkages. However, it should also be acknowledged that this particular, hospital-based, sub-acute recovery-oriented program is not likely to be suitable for everyone, nor, for that matter, are collaborative assessment tools such as the MHRS [45].

\section{Recovery needs, priorities and changes}

The MHRS plays a central role within ISMHU, providing a basis for: calibrating stage-of-change; prioritising intervention plans; characterising the nature of the ISMHU programs on offer (with respect to MHRS domains); and for analysing change. Moreover, the MHRS was generally well received by clients and staff - mirroring experiences elsewhere $[45,46]$. The newly identified MHRS subscales (see Additional file 2) may also prove useful in both clinical and research settings.

The MHRS admission profiles in Table 3 are highly consistent with those reported in a UK study of 203 clients with moderate to severe $\mathrm{MH}$ problems attending 
a range of community-based $\mathrm{MH}$ services [36]. These domain profiles are also similar to the needs identified in a population of severely mentally ill in Sweden over a 10-year period [47]. Mean improvement in overall MHRS scores (of 1.27) was similar to that reported for interventions delivered over a three-month period by specialised recovery clinicians [46]. Improvements on the MHRS Symptom management and functioning subscale were more marked, but all of the subscales displayed significant improvement from admission to discharge (see Table 4).

Improvements on the MHRS Self-belief subscale were somewhat smaller, possibly suggesting that these domains are harder to shift; however, mean scores on this subscale were also higher on admission, with potentially less need or room for change. Importantly, at discharge, the mean number of MHRS items remaining at the preaction stage was only 1.95 (out of 10), suggestive of a substantial change in recovery trajectories or potentially a 'turning point' associated with the ISMHU program.

The MHRS subscale change scores for Symptom management and functioning, Self-belief and Social connection were all significantly moderately correlated (0.626-0.679, see Table 4); however, they relate to one 'change timeframe' (ie, across the course of a targeted 6-week admission). It is anticipated that differential change patterns will be more likely to occur over a longer period of time, as different external factors influence different recovery domains. Consequently, evaluations of underlying recovery components should be considered when examining sustained change, using MHRS subscale and overall scores, together with other psychosocial functioning indices and evaluation methods.

With respect to current functioning, the ISMHU clinicians rated the majority of clients within the 'mild' HoNOS category on admission, which is consistent with the unit's sub-acute focus; notwithstanding, there were detectable HoNOS changes at discharge, with two-fifths (42.7\%) displaying clinically meaningful improvement [43]. Conversely, one-in-ten (10.4\%) ISMHU clients were transferred back to an acute inpatient facility, which is comparable to the $6.0 \%$ to $10.7 \%$ rates from other Australian units $[48,49]$.

\section{Study limitations}

Limitations include: fluctuations in available service data (eg, 154 admissions, 131 MHRS admission ratings, 94 admission/discharge data pairs); no post-discharge assessments; lack of a comparison group; and reliance on data from a single service. The absence of correlations between change scores from clinicians and clients (using different measures) suggests that they tend to have different perspectives; indeed, clients' and clinicians' perceptions of recovery have previously been found to differ
[50]. Further strengthening of the overall measurement approach may be required. For example, a wider variety of domains may need to be assessed from multiple perspectives (eg, current symptoms from a client perspective, and perceived hope and preparedness to change from a clinician-based perspective).

\section{Conclusions}

This paper provides an initial characterisation of a new sub-acute inpatient $\mathrm{MH}$ unit and 6-week program. In broad terms, the findings are reassuring (eg, successful ISMHU establishment; implementation of targeted, acceptable and valued programs; detectable MHRS and HoNOS improvements); however, these findings are also preliminary and largely descriptive. Potential future directions include: examination of relationships between the intensity of program engagement during the ISMHU stay and personal and service outcomes; inclusion of post-ISMHU follow-up assessments; evaluation of other factors affecting and reflecting recovery processes (eg, engagement, self-determination); and further analysis of the impact of ISMHU admissions on recovery trajectories (eg, symptom profiles, service contacts and admissions during the two years either side of the index ISMHU admission). In the meantime, implementation of our broader IRM within a sub-acute setting has undoubtedly strengthened our services' recovery-oriented practices for individuals with a SMI.

\section{Additional files}

Additional file 1: The Intermediate Stay Mental Health Unit Establishment, Service Context, Staffing and Training Strategy. (DOCX 45 kb)

Additional file 2: Mental Health Recovery Star (MHRS) Dimensionality Explorations using data from the Intermediate Stay Mental Health Unit. (DOCX $84 \mathrm{~kb})$

\section{Abbreviations}

CHIME: Clinical information and management exchange; EBIs: Evidencebased interventions; HoNOS: Health of the Nation Outcomes Scales; ICD-10: International Classification of Diseases; IPMS: Inpatient management system; IRM: Integrated recovery-oriented model; ISMHU: Intermediate stay mental health unit; K10: Kessler psychological distress scale; MH: Mental health; MHRS: Mental health recovery star; SMI: Serious mental illness

\section{Acknowledgements}

Thank you to all of the staff from Hunter New England Mental Health services, and the clients and carers who contributed directly or indirectly to this project. We wish to specifically thank Graham Cant for his contribution to the development of the service model, and Anthony Landers, Gemma Howard and Belinda McLachlan, who assisted with data extraction.

Funding

No external funding was received for this project.

Availability of data and materials

While datasets from this project are not publicly available, we will undertake reasonable requests for additional analyses. 


\section{Authors' contributions}

BGF: initiated the project, contributed to project design, implementation, interpretation and drafting of the manuscript. MT: initiated the project, contributed to project design, implementation, data collection, interpretation and manuscript revision. KAS and TJL: contributed to project design, data collection, statistical analysis and interpretation, manuscript preparation and revision. AMC: contributed to project design, interpretation and manuscript revision. SJ and KP: contributed to project implementation, and manuscript revision. ST and SR: contributed to project design, interpretation and manuscript revision. All authors read and approved the final manuscript.

\section{Competing interests}

The authors declare that they have no competing interests.

\section{Consent for publication}

Not applicable, as the data analyses undertaken do not report any individual's data.

\section{Ethics approval and consent to participate}

This project received confirmation from Hunter New England Human Research Ethics Committee that it was exempt from formal review (letter dated October 24th 2013), being viewed as part of an internal, low risk, service evaluation. Upon admission to ISMHU, clients were provided with an information booklet and asked to sign a program participation agreement: however, they were free to withhold consent for any individual measures or program components. Routine service and outcome data were collected in accordance with the NSW Health Records and Information Privacy Act 2002.

\section{Author details}

${ }^{1}$ School of Psychology, Faculty of Science and Technology, University of Newcastle, Callaghan, NSW 2308, Australia. ${ }^{2}$ Centre for Brain and Mental Health Research, University of Newcastle, Callaghan, NSW 2308, Australia. ${ }^{3}$ Hunter New England Mental Health, Newcastle, NSW 2300, Australia. ${ }^{4}$ School of Medicine and Public Health, Faculty of Health and Medicine, University of Newcastle, Callaghan, NSW 2308, Australia. ${ }^{5}$ Nurse Unit Manager (2010-2015), ISMHU, Hunter New England Mental Health, Newcastle, NSW 2300, Australia. ${ }^{6} \mathrm{MH}-\mathrm{READ}$ Unit, Centre for Brain and Mental Health Research, Hunter New England Mental Health and the University of Newcastle, Callaghan, NSW 2308, Australia.

Received: 21 November 2015 Accepted: 8 December 2016 Published online: 03 January 2017

\section{References}

1. Bellack AS. Scientific and consumer models of recovery in schizophrenia: Concordance, contrasts, and implications. Schizophr Bull. 2006;32:432-42.

2. Calabrese J, Corrigan P. Beyond dementia praecox: findings from long-term follow-up studies of schizophrenia. In: Ralph R, Corrigan P, editors. Recovery in mental illness: broadening our understanding of wellness. Washington, DC: American Psychological Association; 2005. p. 63-84.

3. Clarke S, Oades LG, Crowe TP. Recovery in mental health: A movement towards well-being and meaning in contrast to an avoidance of symptoms. Psychiatr Rehabil J. 2012;35:297-304.

4. Davidson L, O'Connell M, Tondora J, Styron T, Kangas K. The top ten concerns about recovery encountered in mental health system transformation. Psychiatr Serv. 2006;57:640-5.

5. Farkas M. The vision of recovery today: what it is and what it means for services. World Psychiatry. 2007;6:68-74.

6. Glover H. Recovery, lifelong learning, empowerment and social inclusion: is a new paradigm emerging? In: Ryan P, Ramon S, Greacen S, editors. Empowerment, lifelong learning and recovery in mental health: towards a new paradigm. London: Palgrave MacMillan; 2012. p. 15-35.

7. Slade M, Williams J, Bird V, Leamy M, Le Boutillier C. Recovery grows up. J Ment Health. 2012;21:99-104.

8. Victorian Department of Health. Framework for recovery-oriented practice. Melbourne: State of Victoria, Department of Health; 2011.

9. Commonwealth of Australia. A national framework for recovery-oriented mental health services: Policy and theory. Canberra: Department of Health and Ageing, CoA; 2013.
10. O'Doherty KY, Doherty TD. Recovering from mental health problems: perceived positive and negative effects of medication on reconnecting with life. Int J Soc Psychiatry. 2011;57:610-8.

11. Weinberg CM. Hope, meaning, and purpose: Making recovery possible. Aust J Rehabil Couns. 2013;36:124-5.

12. Copic V, Deane FP, Crowe TP, Oades LG. Hope, meaning and responsibility across stages of recovery for individuals living with an enduring mental illness. Aust J Rehabil Couns. 2011;17:61-73.

13. Jose D, Ramachandra, Lalitha K, Gandhi S, Desai G, Nagarajaiah. Consumer perspectives on the concept of recovery in schizophrenia: A systematic review. Asian J Psychiatry. 2015;14:13-8.

14. Frost BG, Tirupati S, Johnston S, Turrell M, Lewin TJ, Sly KA, Conrad AM. An Integrated Recovery-oriented Model (IRM) for mental health services: evolution and challenges. BMC Psychiatry (In Press) 2016. DOI 10.1186/s12888-016-1164-3.

15. National Mental Health Commission. The national review of mental health programmes and services. Sydney: NMHC; 2014.

16. Commonwealth of Australia. Development of the Australian Mental Health Care Classification - public consultation paper 1. Canberra: Independent Hospital Pricing Authority, CoA; 2015.

17. Commonwealth of Australia. Consultation paper on the Pricing Framework for Australian Public Hospital Services 2016-17. Canberra: Independent Hospital Pricing Authority, CoA; 2015.

18. Commonwealth of Australia. A national framework for recovery-oriented mental health services: Guide for practitioners and providers. Canberra: Department of Health and Ageing, CoA; 2013.

19. Le Boutillier C, Leamy M, Bird VJ, Davidson L, Williams J, Slade M. What does recovery mean in practice? A qualitative analysis of international recoveryoriented practice guidance. Psychiatr Serv. 2011;62:1470-6.

20. Joint Commissioning Panel for Mental Health. Guidance for commissioners of rehabilitation services for people with complex mental health needs, Volume 2: Practical mental health commissioning. In: Book Guidance for commissioners of rehabilitation services for people with complex mental health needs, Volume 2: Practical mental health commissioning. vol. 2. London: JCP-MH, Royal College of General Practitioners and Royal College of Psychiatrists; 2012.

21. Royal College of Psychiatrists. Enabling recovery for people with complex mental health needs: A template for rehabilitation services (Faculty Report FR/RS/1). In: Book Enabling recovery for people with complex mental health needs: A template for rehabilitation services (Faculty Report FR/RS/1). London: Faculty of Rehabilitation and Social Psychiatry, RC Psych; 2009.

22. Jablensky A, McGrath J, Herrman H, Castle D, Gureje O, Evans M, Carr V, Morgan V, Korten A, Harvey C. Psychotic disorders in urban areas: An overview of the study on low prevalence disorders. Aust N Z J Psychiatry. 2000;34:221-36.

23. Matheson SL, Shepherd AM, Carr VJ. How much do we know about schizophrenia and how well do we know it? Evidence from the Schizophrenia Library. Psychol Med. 2014;44:3387-405.

24. Harrow M, Grossman LS, Jobe TH, Herbener ES. Do patients with schizophrenia ever show periods of recovery? A 15-year multi-follow-up study. Schizophr Bull. 2005;31:723-34.

25. Lieberman JA, Drake RE, Sederer LI, Belger A, Keefe R, Perkins D, Stroup S. Science and recovery in schizophrenia. Psychiatr Serv. 2008:59:487-96.

26. Drake RE, Whitley R. Recovery and severe mental illness: description and analysis. Can J Psychiatry. 2014;59:236-42.

27. Mueser KT, Deavers F, Penn DL, Cassisi JE. Psychosocial treatments for schizophrenia. Annu Rev Clin Psychol. 2013;9:465-97.

28. Gilburt H, Slade M, Bird V, Oduola S, Craig TK. Promoting recovery-oriented practice in mental health services: a quasi-experimental mixed-methods study. BMC Psychiatry. 2013;13:167.

29. Borg M, Kristiansen K. Recovery-oriented professionals: Helping relationships in mental health services. J Ment Health. 2004;13:493-505.

30. Mental Health Coordinating Council. Submission to NSW Health: Proposal to Pilot a Community Managed Step-up and Home based Outreach (Sub-acute) Mental Health Service in New South Wales (2011-2014). Sydney: Mental Health Coordinating Council; 2010.

31. NSW Department of Health. A New Direction for Mental Health. Sydney: NSW Health; 2006

32. Panesar N, Valachova I, Lynch W, Pai N. Establishing a recovery-focused rehabilitation unit: A case example. Aust J Rehabil Couns. 2011;17:46-53.

33. MacKeith J, Burns S, editors. Mental health recovery star; user guide. 2nd ed. London: Triangle Consulting and Mental Health Providers Forum; 2010. 
34. Onifade Y. The mental health recovery star. Ment Health Soc Incl. 2011;15:78-87.

35. Connors G, Donovan D, DiClemente C. Substance abuse treatment and the stages of change: selecting and planning interventions. New York: Guilford Press; 2001.

36. Dickens G, Weleminsky J, Onifade Y, Sugarman P. Recovery Star: Validating user recovery. Psychiatrist. 2012;36:45-50.

37. Killaspy H, White S, Taylor TL, King M. Psychometric properties of the Mental Health Recovery Star. Br J Psychiatry. 2012;201:65-70.

38. Burgess P, Pirkis J, Coombs T. Routine outcome measurement in Australia. Int Rev Psychiatry. 2015;27:264-75.

39. Wing JK, Beevor AS, Curtis RH, Park SB, Hadden S, Burns A. Health of the Nation Outcome Scales (HoNOS). Research and development. Br J Psychiatry. 1998;172:11-8.

40. Kessler RC, Andrews G, Colpe L, Hiripi E, Mroczek DK, Normand SL, Walters EE, Zaslavsky AM. Short screening scales to monitor population prevalences and trends in non-specific psychological distress. Psychol Med. 2002;32:959-76.

41. Orrell M, Yard P, Handysides J, Schapira R. Validity and reliability of the Health of the Nation Outcome Scales in psychiatric patients in the community. Br J Psychiatry. 1999;174:409-12.

42. Pirkis JE, Burgess PM, Kirk PK, Dodson S, Coombs TJ, Williamson MK. A review of the psychometric properties of the Health of the Nation Outcome Scales (HoNOS) family of measures. Health Qual Life Outcomes. 2005;3:76.

43. Parabiaghi A, Kortrijk HE, Mulder CL. Defining multiple criteria for meaningful outcome in routine outcome measurement using the Health of the Nation Outcome Scales. Soc Psychiatry Psychiatr Epidemiol. 2014:49:291-305.

44. Kilian R, Lauber C, Kalkan R, Dorn W, Rossler W, Wiersma D, van Buschbach JT, Fioritti A, Tomov T, Catty J, Burns T, Becker T. The relationships between employment, clinical status, and psychiatric hospitalisation in patients with schizophrenia receiving either IPS or a conventional vocational rehabilitation programme. Soc Psychiatry Psychiatr Epidemiol. 2012;47:1381-9.

45. Tickle A, Cheung N, Walker C. Professionals' perceptions of the mental health recovery star. Ment Health Rev J. 2013;18:194-203.

46. Lloyd C, Williams PL, Machingura T, Tse S. A focus on recovery: using the Mental Health Recovery Star as an outcome measure. Adv Ment Health. 2016;14(1):57-64.

47. Arvidsson $\mathrm{H}$. The development of needs in a group of severely mentally ill. A 10-year follow-up study after the 1995 Swedish mental health care reform. Soc Psychiatry Psychiatr Epidemiol. 2008;43:705-13.

48. Lee SJ, Collister L, Stafrace S, Crowther E, Kroschel J, Kulkarni J. Promoting recovery via an integrated model of care to deliver a bed-based, mental health prevention and recovery centre. Australas Psychiatry. 2014;22:481-8.

49. Thomas K, Rickwood DJ, Bussenschutt G. Adult step-up step-down: A sub-acute short-term residential mental health service. Int J Psychosoc Rehabil. 2015;19:13-21.

50. Andresen R, Caputi P, Oades LG. Do clinical outcome measures assess consumer-defined recovery? Psychiatry Res. 2010;177:309-17.

\section{Submit your next manuscript to BioMed Central and we will help you at every step:}

- We accept pre-submission inquiries

- Our selector tool helps you to find the most relevant journal

- We provide round the clock customer support

- Convenient online submission

- Thorough peer review

- Inclusion in PubMed and all major indexing services

- Maximum visibility for your research

Submit your manuscript at www.biomedcentral.com/submit 